\title{
Development of Thiazolidinones as Fungal Carbonic Anhydrase Inhibitors
}

\author{
Özlen Güzel-Akdemir ${ }^{1}$, Simone Carradori ${ }^{2}{ }^{-}$, Rossella Grande ${ }^{2}{ }^{\circledR}$, Kübra Demir-Yazıc1 ${ }^{1}$, \\ Andrea Angeli ${ }^{3,4}{ }^{\circ}$, Claudiu T. Supuran ${ }^{3}\left(\mathbb{D}\right.$ and Atilla Akdemir ${ }^{5, *(\mathbb{D}}$
}

1 Istanbul University, Department of Pharmaceutical Chemistry, Faculty of Pharmacy, 34116 Istanbul, Turkey; oguzel@istanbul.edu.tr (Ö.G.-A.); kubra.demir@istanbul.edu.tr (K.D.-Y.)

2 Dipartimento di Farmacia, “G. d'Annunzio" University of Chieti-Pescara, Via dei vestini 31, 66100 Chieti, Italy; simone.carradori@unich.it (S.C.); rossella.grande@unich.it (R.G.)

3 Neurofarba Department, Section of Pharmaceutical and Nutraceutical Sciences, Università degli Studi di Firenze, Via U. Schiff 6, 50019 Sesto Fiorentino (Florence), Italy; andrea.angeli@unifi.it (A.A.); claudiu.supuran@unifi.it (C.T.S.)

4 Centre of Advanced Research in Bionanoconjugates and Biopolymers Department, "Petru Poni" Institute of Macromolecular Chemistry, 700487 Iasi, Romania

5 Bezmialem Vakif University, Computer-aided drug discovery laboratory, Department of Pharmacology, Faculty of Pharmacy, 34093 Istanbul, Turkey

* Correspondence: aakdemir@bezmialem.edu.tr; Tel.: +90-212-523-2288 (ext. 3142)

Received: 27 March 2020; Accepted: 20 April 2020; Published: 22 April 2020

check for updates

\begin{abstract}
In our efforts to find new and selective thiazolidinone-based anti-Candida agents, we synthesized and tested 26 thiazolidinones against several Candida spp. and Gram-positive and Gram-negative bacteria. The compounds showed selective antifungal activity with potency similar to fluconazole and clotrimazole, while lacking strong antibacterial activity. Molecular docking and molecular dynamics studies were performed on Candida CYP51a1 and carbonic anhydrase (CA) enzymes to further suggest putative targets that could mediate the antifungal effects of these compounds. Finally, the compounds were tested in enzyme inhibition assays to assess their putative mechanism of action and showed promising $K_{I}$ values in the $0.1-10 \mu \mathrm{M}$ range against the Candida glabrata $\beta$-CA enzyme CgNce103.
\end{abstract}

Keywords: 4-thiazolidinones; antifungal activity; molecular modelling studies; carbonic anhydrases; lanosterol 14 $\alpha$-demethylase; CYP51a1; CgNce103

\section{Introduction}

Candida species are harmless commensals in humans but can represent the most common causative agents of hospital-acquired invasive fungal infections. Indeed, Candida spp. are involved in opportunistic infections that cause, in immunocompromised individuals, morbidity and, in some cases, mortality, as well as an increase of the healthcare costs because of a prolonged hospitalization $[1,2]$. Furthermore, the incidence of the infections associated with Candida spp. increased over the past three decades due to the large use of immunomodulatory agents, extensive use of broad-spectrum antimicrobial drugs, and central vascular catheters [2]. Candida albicans represents the most common cause of invasive candidiasis in the United States of America, followed by C. glabrata, C. parapsilosis, and $C$. tropicalis [3,4]. Antifungal resistance increased over time also because of the empiric, routine prophylactic, and widespread use of antifungal-based pesticides [5].

Azole antifungal agents have been employed clinically for over 50 years; therefore, due to the development of resistant strains, the rates of mortality associated with the fungal invasive infections reached more than 50\% [6,7]. The azoles are an important class of antifungal drugs that target lanosterol 
$14 \alpha$-demethylase (CYP51a1) [8]. This enzyme plays a pivotal role in the biosynthesis pathway of ergosterol, which is a major constituent of the fungal cell membrane. however, drug resistance has become a crucial issue for this class of compounds due to their massive use as first-line therapy. Candida spp. developed three main strategies to become resistant to azoles: the first one is the production of multidrug pumps, which, once introduced in the fungal cell wall, allow pumping out the antimicrobial; the second one is associated with the mutation or upregulation of the genes encoding for the target enzyme promoting the alteration of the binding site, thus lowering the affinity of the drug; the third one consists in the development of an alternative pathway that is not blocked by the action of the azoles [9].

An innovative and emerging target enzyme for promising antifungal drugs and surface disinfectants are carbonic anhydrases belonging to the $\beta$-family ( $\beta$-CA) and deriving from Candida species, such as Candida albicans CA (CaNce103) and Candida glabrata CA (CgNce103) and their ortholog ScNce103 from Saccharomyces cerevisiae [10-12]. Indeed, pathogenic yeasts can survive and proliferate in environments characterized by diverse carbon dioxide $\left(\mathrm{CO}_{2}\right)$ concentrations accelerating the spontaneous and reversible conversion of $\mathrm{CO}_{2}$ to bicarbonate, subsequently used in cellular metabolism, with the help of this metalloenzyme. C. albicans and Saccharomyces cerevisiae cannot survive in atmospheric air $\left(0.0391 \%\right.$ of $\left.\mathrm{CO}_{2}\right)$ and in human blood (up to $5.5 \%$ of $\left.\mathrm{CO}_{2}\right)$ with a nonfunctional or inactivated carbonic anhydrase (CA, EC 4.2.1.1). Conversely, the expression of this enzyme in C. glabrata is regulated by the environmental $\mathrm{CO}_{2}$ both at the protein and transcription level but independent from the cAMP-PKA pathway [13]. Moreover, the crystal structure of recombinant CaNce103p, prepared in Escherichia coli, was determined at a $2.2 \AA$ resolution [14]. It forms a zinc-containing homotetramer organized as a dimer of dimers, characterized by a slightly longer and narrower channel-like active site cavity at the bottom of which is situated the tetrahedrally coordinated zinc ion crucial for catalysis. The structural knowledge of this CA has prompted the design and synthesis of selective inhibitors, which should display a limited affinity toward mammalian $\alpha$-CAs. These natural and synthetic CA inhibitors (CAIs) were active in the micromolar or nanomolar range and incorporated different chemical scaffolds such as sulphonamides [15-21], anions [22], carboxylic acids [23-25], dithiocarbamates [26], boronic acids [27-29], phenols [30], and phosphonamidates [31]. Recently, compounds not characterized by the presence of zinc binding groups were also shown to selectively inhibit the fungal CA isoforms in the micromolar range [32-35], leading to an opportunity to avoid cross-inhibition with structurally related human $\alpha$-CAs. In the search of new chemical scaffolds, some of us proposed new thiazolidinone compounds, well-known as antimicrobial agents [36], as inhibitors of the human CAs [37], keeping in mind that this chemotype was shown to be endowed with a promising anti-Candida activity [38,39].

In the present work, we assessed the in vitro selective antifungal activity of previously synthesized $N^{\prime}$-[3-(4-substituted phenyl)-4-oxo-1,3-thiazolidin-2-ylidene]-2-hydroxy-2-phenylacetohydrazide and $N^{\prime}$-[3-(4-substitutedphenyl)-5-methyl-4-oxo-1,3-thiazolidin-2-ylidene] -2-hydroxy-2-phenylaceto- hydrazide derivatives (Figure 1) against sixteen clinical strains of representative Candida species (C. albicans, C. tropicalis, C. parapsilosis, C. sakè, and C. glabrata) and their putative mechanism of action based on the in vitro inhibition of the fungal $\beta$-carbonic anhydrase [37]. To further improve the knowledge of the biological potential of this scaffold, we also aimed at evaluating in vitro the additional inhibitory activity against Gram-positive and Gram-negative bacteria and in silico the peculiar binding mode and relevant interactions with fungal CYP51a1 (lanosterol $\alpha$-demethylase) from C. glabrata and C. albicans and Candida glabrata CA (CgNce103) enzyme. 


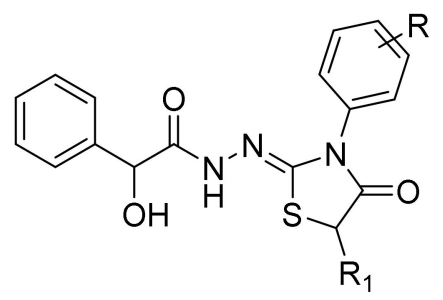

Figure 1. The general chemical structures of novel compounds $3 \mathrm{a}-3 \mathrm{o}$ and $4 \mathrm{a}-4 \mathrm{k}$.

\section{Results and Discussion}

\subsection{Microbiology}

Pursuing our efforts in the discovery of innovative antifungal agents, we evaluated the susceptibility of several clinical Candida and bacterial species to our novel compounds by determining their minimum inhibitory concentration (MIC) by the broth microdilution method in vitro. Firstly, derivatives, dissolved in dimethylsulfoxide (DMSO), were evaluated for their antibacterial activity. Twenty-four routine clinical Gram-positive (Staphylococcus aureus and Staphylococcus epidermidis) and Gram-negative isolates (Escherichia coli and Enterobacter spp.) were tested following the experimental procedures previously reported [38]. Then, the antifungal activity was evaluated against sixteen clinical fungal isolates of the most relevant Candida spp. (C. albicans, C. tropicalis, C. parapsilosis, C. sakè, and C. glabrata) and compared with topical and systemic reference drugs clotrimazole and fluconazole, respectively (Table 1 ).

Table 1. Minimum inhibitory concentration (MIC) of newly synthesized compounds (3a-3o and 4a-4k), clotrimazole, and fluconazole against sixteen clinical strains of Candida species.

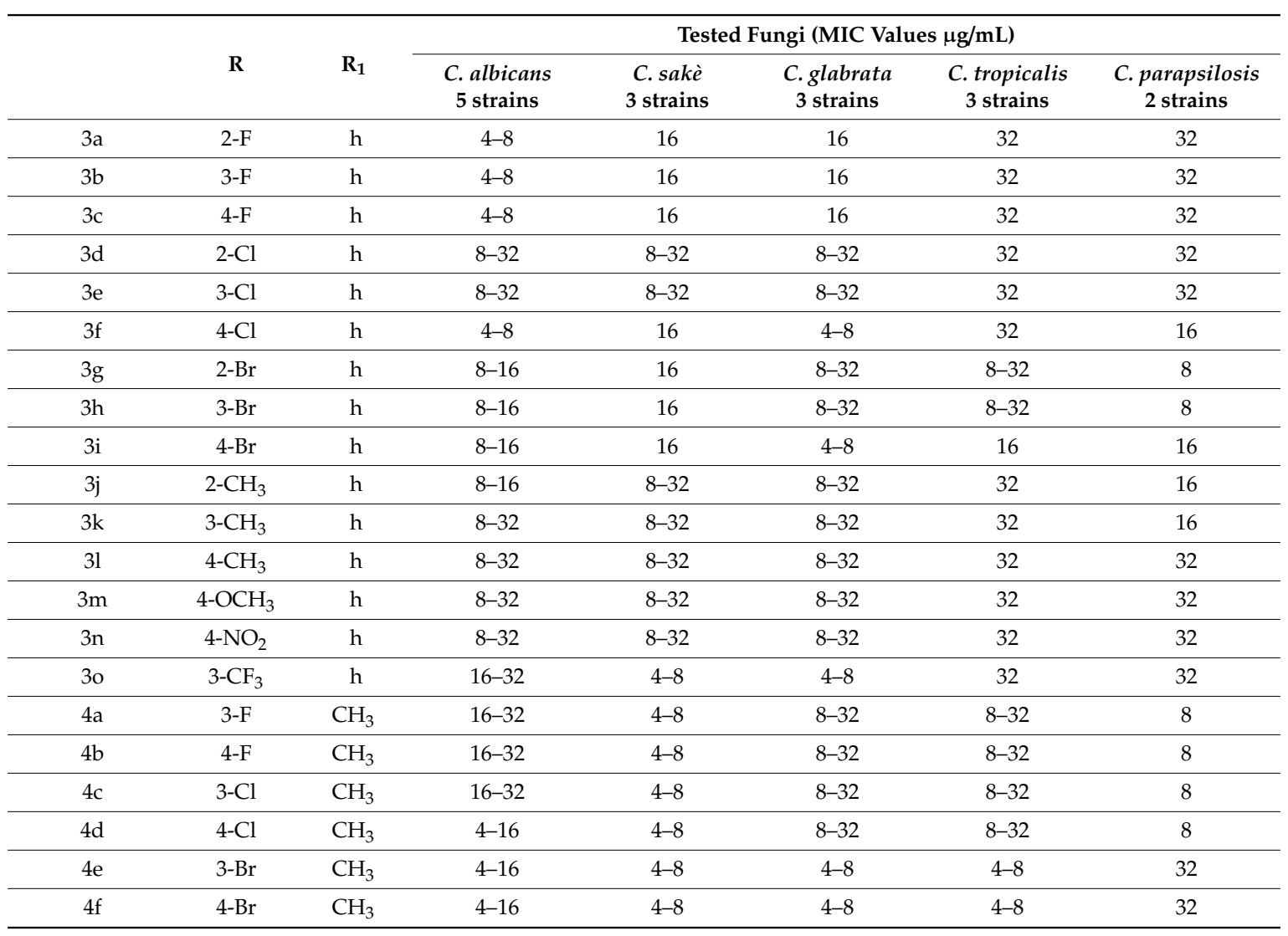


Table 1. Cont.

\begin{tabular}{|c|c|c|c|c|c|c|c|}
\hline & \multirow[b]{2}{*}{$\mathbf{R}$} & \multirow[b]{2}{*}{$\mathbf{R}_{1}$} & \multicolumn{5}{|c|}{ Tested Fungi (MIC Values $\mu \mathrm{g} / \mathrm{mL}$ ) } \\
\hline & & & $\begin{array}{l}\text { C. albicans } \\
5 \text { strains }\end{array}$ & $\begin{array}{c}\text { C. sakè } \\
3 \text { strains }\end{array}$ & $\begin{array}{l}\text { C. glabrata } \\
3 \text { strains }\end{array}$ & $\begin{array}{l}\text { C. tropicalis } \\
3 \text { strains }\end{array}$ & $\begin{array}{c}\text { C. parapsilosis } \\
2 \text { strains }\end{array}$ \\
\hline $4 \mathrm{~g}$ & $3-\mathrm{CH}_{3}$ & $\mathrm{CH}_{3}$ & $4-16$ & $4-8$ & $4-8$ & $4-8$ & 32 \\
\hline $4 \mathrm{~h}$ & $4-\mathrm{CH}_{3}$ & $\mathrm{CH}_{3}$ & $8-32$ & $8-32$ & $8-32$ & 16 & 32 \\
\hline $4 \mathrm{i}$ & $4-\mathrm{OCH}_{3}$ & $\mathrm{CH}_{3}$ & $8-32$ & $8-32$ & $8-32$ & 16 & 32 \\
\hline $4 \mathrm{j}$ & $4-\mathrm{NO}_{2}$ & $\mathrm{CH}_{3}$ & $8-32$ & $8-32$ & $8-32$ & 16 & 32 \\
\hline $4 \mathrm{k}$ & $3-\mathrm{CF}_{3}$ & $\mathrm{CH}_{3}$ & $32-128$ & $8-32$ & $8-32$ & 128 & 64 \\
\hline Clotrimazole & & & 2 & 2 & 2 & 2 & 2 \\
\hline Fluconazole ${ }^{a}$ & & & 2 & 2 & 2 & 2 & 2 \\
\hline
\end{tabular}

All compounds did not display any antibacterial activity against Gram-positive or Gram-negative clinical isolates (MIC $\geq 256 \mu \mathrm{g} / \mathrm{mL}$ ), disregarding the substitution pattern and with respect to the standard drug ceftazidime (MIC $=4-8 \mu \mathrm{g} / \mathrm{mL}$ ). A slightly better inhibitory activity versus $\mathrm{S}$. epidermidis strains can be observed for compounds $4 \mathrm{c}, 4 \mathrm{~d}, 4 \mathrm{i}$, and $4 \mathrm{j}$ characterized by the presence of $\mathrm{R}_{1}=\mathrm{CH}_{3}$ on the $\mathrm{C} 5$ of the thiazolidinone nucleus (MIC $=128 \mu \mathrm{g} / \mathrm{mL}$ ). Thus, the further comparison with the results for antifungal activity in Table 1 suggested a selective action restricted to Candida spp., as corroborated by the inefficacy against bacterial species. Comparing the two series of derivatives ( 3 and 4), the introduction of a methyl moiety at the $\mathrm{C} 5$ of thiazolidinone usually led to lower MIC values against the five fungal species, whereas the C5-unsubstituted thiazolidinones were poor inhibitors of the growth of $C$. tropicalis, $C$. parapsilosis, and C. sakè. Among the compounds belonging to series 3 $\left(\mathrm{R}_{1}=\mathrm{H}\right)$, derivatives 3a-3c $(\mathrm{R}=2-\mathrm{F}, 3-\mathrm{F}$, and $4-\mathrm{F}$, respectively $)$ and $3 \mathrm{f}(\mathrm{R}=4-\mathrm{Cl})$ displayed the most interesting inhibitory activity ( $\mathrm{MIC}=4-8 \mu \mathrm{g} / \mathrm{mL}$ ) against all $\mathrm{C}$. albicans strains. Conversely, other substituents such as $\mathrm{Br}, \mathrm{CH}_{3}, \mathrm{OCH}_{3}, \mathrm{NO}_{2}$, and $\mathrm{CF}_{3}$ furnished less-active compounds (MIC range values of $8-32 \mu \mathrm{g} / \mathrm{mL})$. Against $C$. glabrata strains, compounds $3 \mathrm{f}(\mathrm{R}=4-\mathrm{Cl}), 3 \mathrm{i}(\mathrm{R}=4-\mathrm{Br})$, and $3 \mathrm{o}\left(\mathrm{R}=3-\mathrm{CF}_{3}\right)$ were the best-in-class inhibitors, showing the lowest MIC range values $(4-8 \mu \mathrm{g} / \mathrm{mL})$ within this series. Compound 3o was also effective in the same MIC range against $C$. sakè strains. On the contrary, series 3 was almost weak versus both $C$. tropicalis and $C$. parapsilosis strains.

The antifungal results for series $4\left(\mathrm{R}_{1}=\mathrm{CH}_{3}\right)$ furnished a more promising scenario. Collectively, they displayed a better inhibitory profile toward all the Candida species under investigation, with MIC range values very similar to the reference drugs clotrimazole and fluconazole $(2 \mu \mathrm{g} / \mathrm{mL})$. The presence of a halogen $(\mathrm{F}, \mathrm{Cl}$, and $\mathrm{Br})$ on the aryl ring at $\mathrm{N} 3$ of the thiazolidinone nucleus induced a remarkable growth inhibition against all Candida spp. and, in particular, versus C. sakè, C. glabrata, and C. tropicalis $\left(\mathrm{MIC}=4-8 \mu \mathrm{g} / \mathrm{mL}\right.$ ). The most interesting results were registered for compounds having a $\mathrm{Cl}, \mathrm{Br}$, or $\mathrm{CH}_{3}$ in the meta or para position of the aryl ring $(4 \mathrm{~d}-4 \mathrm{~g})$. Conversely, compounds with other substitution patterns were shown to be less potent.

Collectively, this cell-based evaluation suggested that thiazolidinone compounds can be regarded as promising selective antifungal agents toward different Candida species. The presence of several chemical groups on the core nucleus could further suggest a proper modulation of the pharmacokinetic and chemical-physical properties suitable for the selection of lead compounds to be clinically investigated.

\subsection{Molecular Modeling Studies to Suggest Putative Targets}

To suggest possible targets that mediate the antifungal activity of the thiazolidinones, we performed docking studies against Candida CYP51a1 and CA enzymes, followed by molecular dynamics simulations. 


\subsubsection{Molecular Modeling Studies of C. albicans and C. glabrata CYP51a1 Enzymes}

Crystal structures of Candida albicans (CaCYP51a1; PDB: 5v5z; 2.9 Å) and Candida glabrata (CgCYP51; PDB: 5jlc; $2.4 \AA$ A) CYP51 enzymes both in complex with itraconazole have been obtained from the RCSB Protein Data Bank. The sequence identity between both enzymes is approximately $64 \%$. however, the sequence identity in the active site (defined as all amino acids within $4.5 \AA$ of itraconazole) is $90 \%$. The overall identity similarity of CaCYP51a1 to the other Candida CYP51 enzymes is between $64-84 \%$, while the sequence identity in the active site is $90-95 \%$.

Docking studies into the active site of CgCYP51a1 did not reveal any poses in which the ligand could directly interact with the iron atom of the haem group. Instead, poses have been obtained in which the ligands are located near the entrance of the cavity (Figure 2A). For example, compound 40 forms a hydrogen bond with the side chain of Arg99 via its carbonyl group. The hydroxyl group ( $S$ isomer) of the ligand is able to form hydrogen-arene interactions with his382 and a hydrogen bond with Tyr73. This interaction is not possible for the $R$ isomer of the compound. Cation- $\pi$ interactions are possible between the substituted phenyl group of the ligand and the side chain of Arg99. hydrophobic interactions are formed with Tyr73, Leu96, Leu97, Phe242, Val243, his382, and Phe385. Other compounds of these series can adopt similar docked poses.
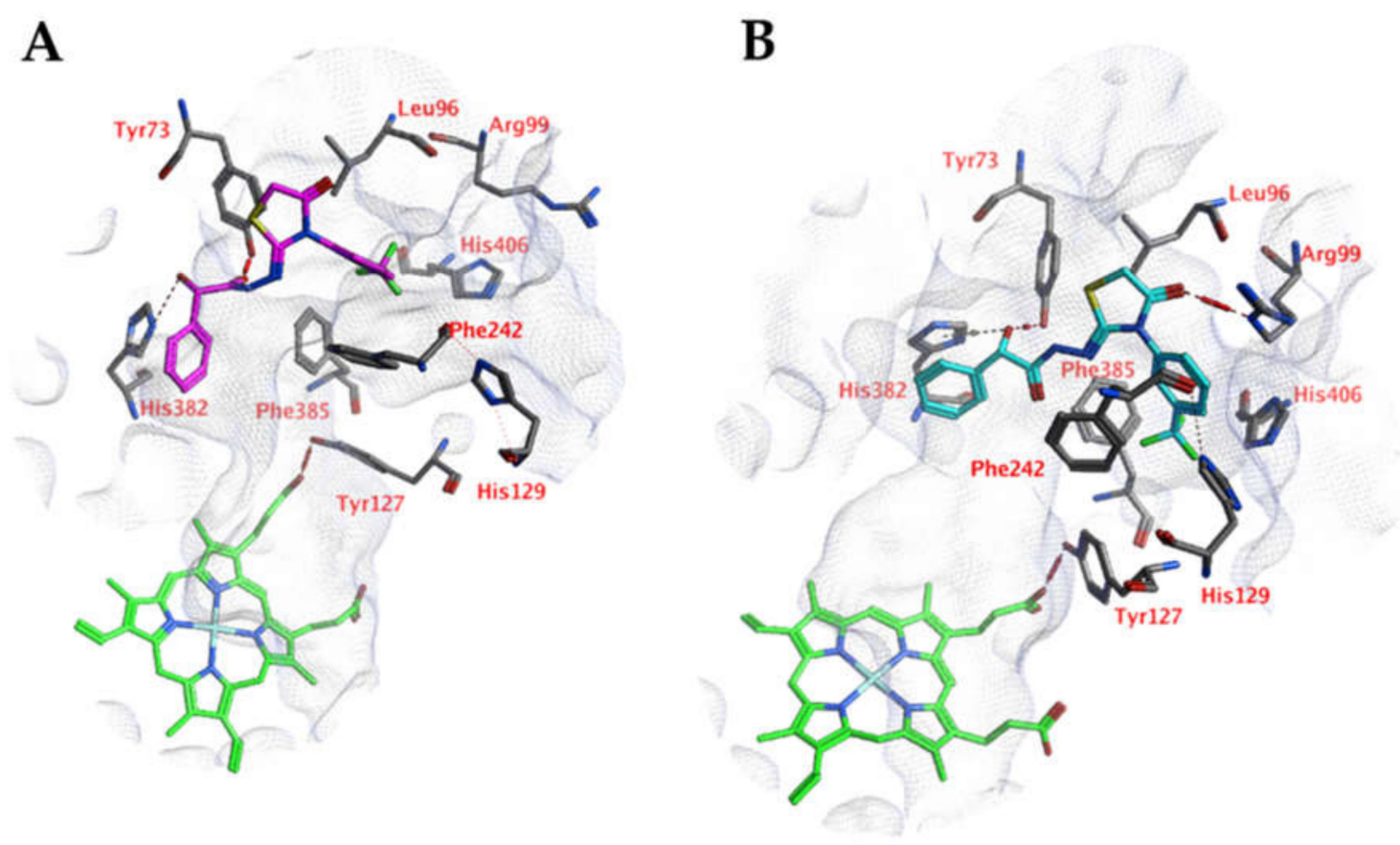

Figure 2. (A) The docked pose of compound 4o (turquoise) in the active site of CgCYP51 (PDB: 5jlc). (B) The docked pose of compound 4o (purple) in the active site of CgCYP51 after a 5-ns molecular dynamics simulation. The haem group is indicated in green sticks. The pocket surface is indicated with a white mesh. hydrogen bonds are indicated in red dashed lines. h-arene interactions are indicated in yellow dashed lines.

Molecular dynamics (MD) simulations indicate that this docked pose is not stable as the ligand RMSD value increases to levels above $3 \AA$ (Figure 3). Early during the simulation (200 ps), the hydrogen bond between the ligand and Arg99 is lost due to the adoption of another sidechain conformation. As a result, the ligand moves closer to his 382 to result in a new binding pose (already observed at $300 \mathrm{ps}$ ). The ligand hydroxyl group forms a hydrogen bond with his 382 ( $86 \%$ of the $5 \mathrm{~ns}$ simulation), while the ligands carbonyl group forms a hydrogen bond with Tyr73 (Figure 2B). This hydrogen bond is observed during $94 \%$ of the 5 ns unconstrained simulation. The peptide bond and the double bond of the ligand are not in plane (bond between the two adjacent nitrogen atoms), while this was expected 
for the $\mathrm{sp}^{2}$ hybridized system. A DFT calculation ( $\omega \mathrm{B} 97 \mathrm{X}-\mathrm{D}$ functional and $6-311+\mathrm{G}^{* *}$ basis set) was performed using Spartan '18 (v1.4.0, WaveFunction Inc., CA, USA) to investigate the bond order between the two adjacent nitrogen atoms, and this was found to be 0.89 (Mulliken bond order). This indicates that the obtained ligand conformation could be possible. Many compounds of series 3 and 4 show similar docked poses, as described for compound 4o (Figure 2A).

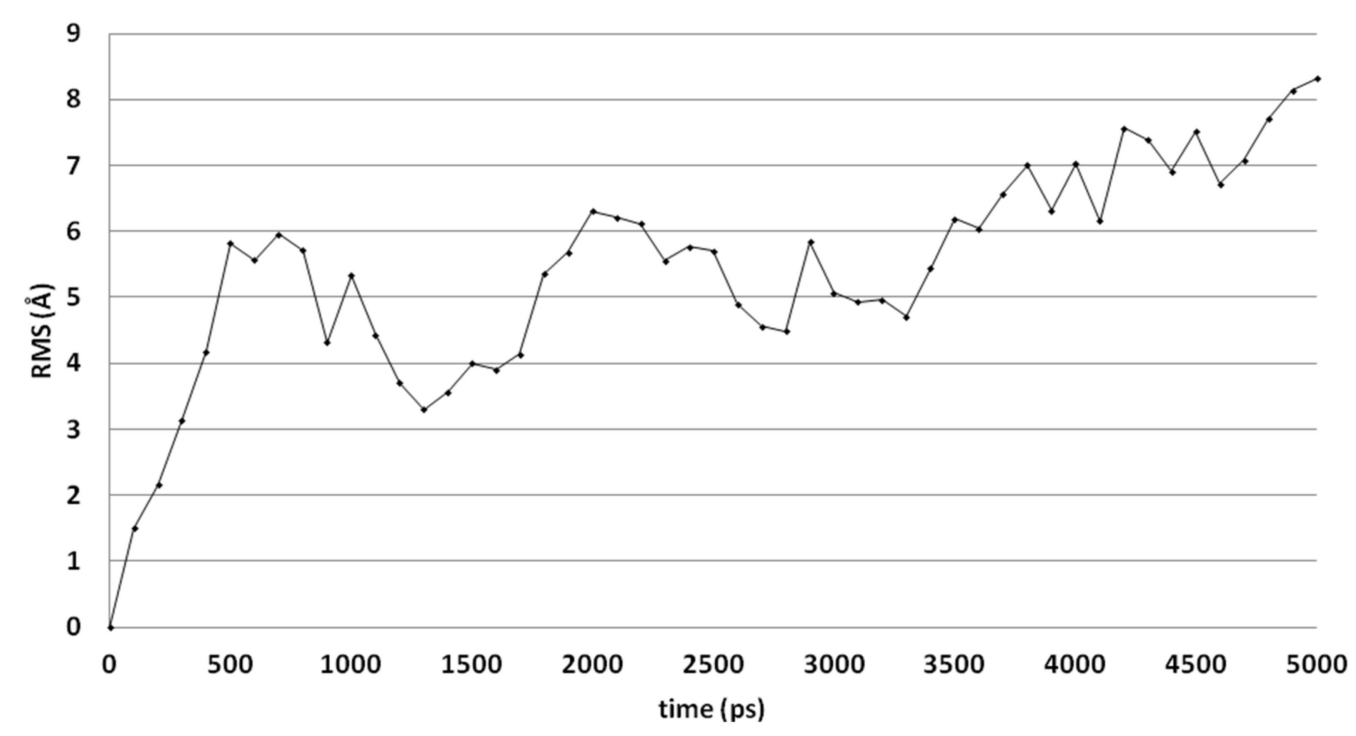

Figure 3. The RMSD of the ligand heavy atoms during the 5-ns molecular dynamics simulation of compound 4o in the active site of CgCYP51.

A comparable docked pose, as observed for compound 4o in the active site of CgCYP51a1 (Figure 2A), has not been observed in the active site of CaCYP51a1 due to the change of Arg99 (CgCYP51a1) to Lys90 (CaCYP51a1). Instead, the ligands enter deeper into the active site, and several ligands form interactions with the haem iron via their carbonyl group (Figure 4, compound 4h). The substituted phenyl group forms hydrophobic interactions with the haem group. The hydroxyl group ( $R$ isomer) forms a hydrogen bond with the carbonyl backbone of Met508 and an intramolecular interaction with the ligand sulfur atom. MD simulations indicate that the interaction between the ligand's carbonyl group and the haem iron is stable during the 5-ns simulation. The intramolecular bond between the hydroxyl group and the sulfur atom is lost early during the simulation (100 ps), while the hydrogen bond with the backbone carbonyl of Met508 is stable only during the first $2700 \mathrm{ps}$ of the simulation. This can also be observed as the RMSD of the ligand heavy atoms increases after 2700 ps (Figure 5). During the MD simulation, a hydrogen bond between the ligand and the backbone carbonyl of Met508 is observed during 70.6\% of the 5-ns simulation, while a hydrogen-arene interaction between the sidechain of Met508 and the unsubstituted phenyl group is observed during $9.8 \%$ of the simulation. Similar docked poses have been observed for the other compounds of series 3 and 4 .

An alternative docked pose in CaCYP51a1 has been observed for compound 4o (Figure 6). hydrogen bonds are observed between the ligand and the backbones of Ser378 and Met508. The trifluorophenyl group is located close to the haem group and forms hydrophobic interactions. MD simulations result in RMSD values around 2.5-3.5 $\AA$ for most of the simulation and indicate that the docked pose is stable (Figure 7). Only the substituted phenyl group is dynamic, as it only forms hydrophobic interactions with haem. The hydrogen bonds with Ser378 and Met508 are not lost during the simulation. The hydrogen bond with the backbone of Met508 is present during the whole duration of the simulation, while the hydrogen bond to the backbone of Ser378 is present during $9.2 \%$. 
A

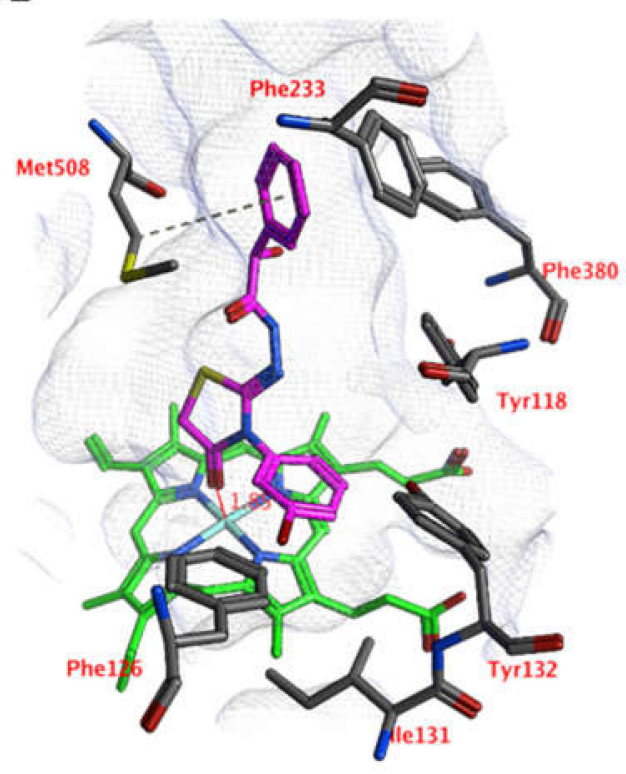

B

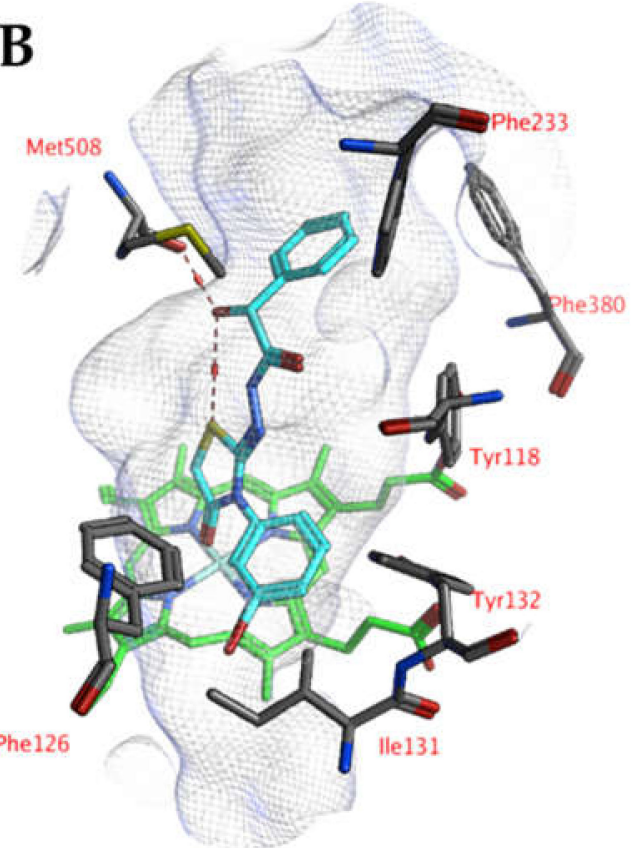

Figure 4. (A) The docked pose of compound 4h (turquoise) in the active site of CaCYP51 (PDB: 5v5z). (B) The docked pose of compound 4 h (purple) after a 5-ns molecular dynamics simulation. The haem group is indicated in green sticks. The pocket surface is indicated with a white mesh. hydrogen bonds are indicated in red dashed lines.

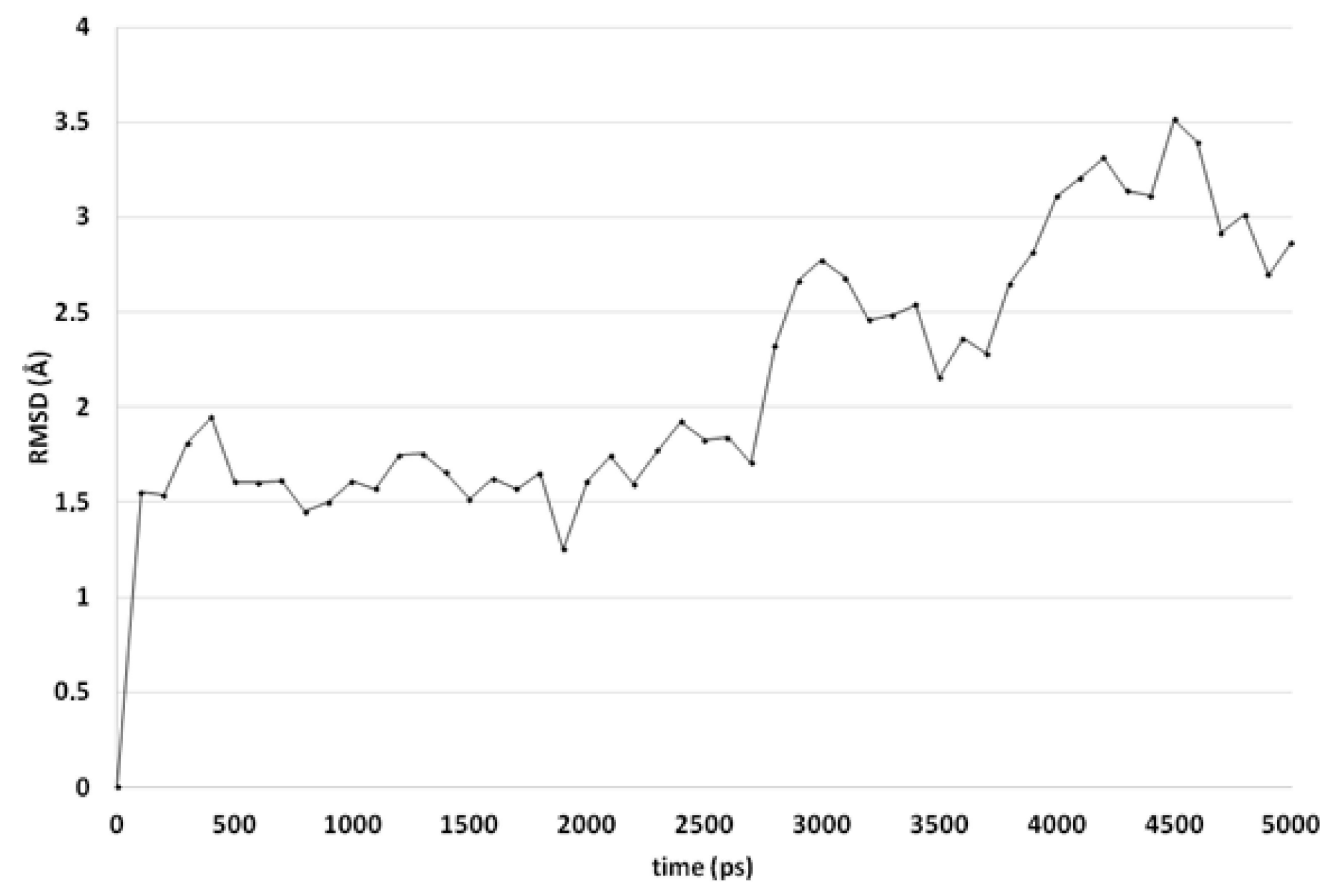

Figure 5. The RMSD of the ligand heavy atoms during the 5-ns molecular dynamics simulation of compound $4 \mathrm{~h}$ in the active site of CaCYP51. 
A

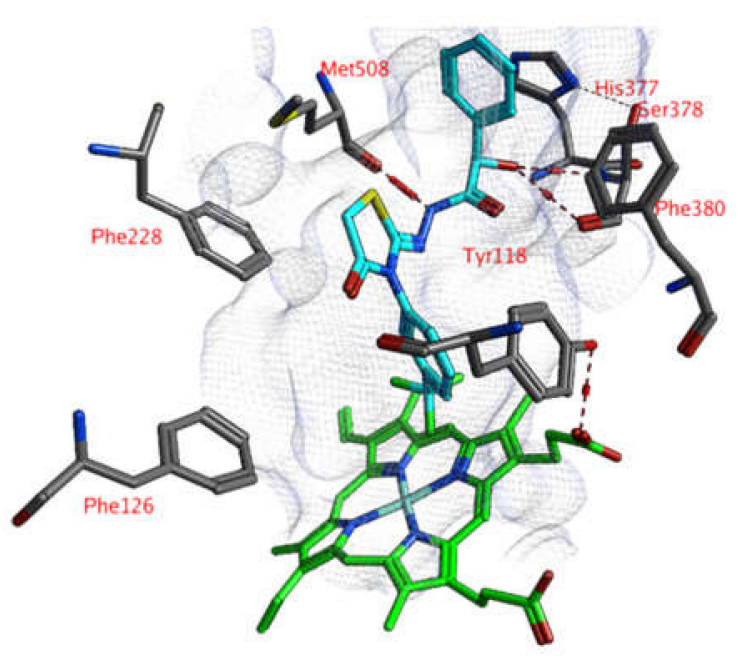

B

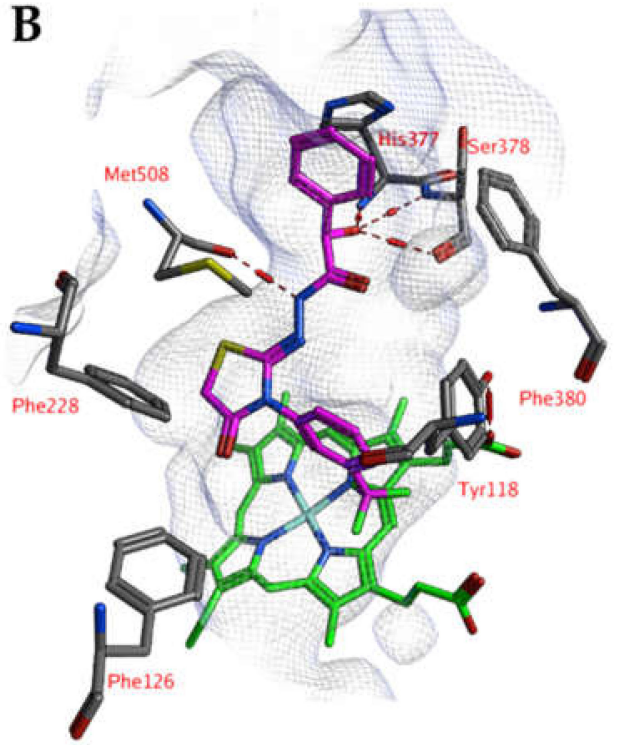

Figure 6. (A) The docked pose of compound 4o (purple) in the active site of CaCYP51 (PDB: 5v5z). (B) The docked pose of compound 4o (turquoise) after a 5-ns molecular dynamics simulation. The haem group is indicated in green sticks. The pocket surface is indicated with a white mesh. hydrogen bonds are indicated in red dashed lines.

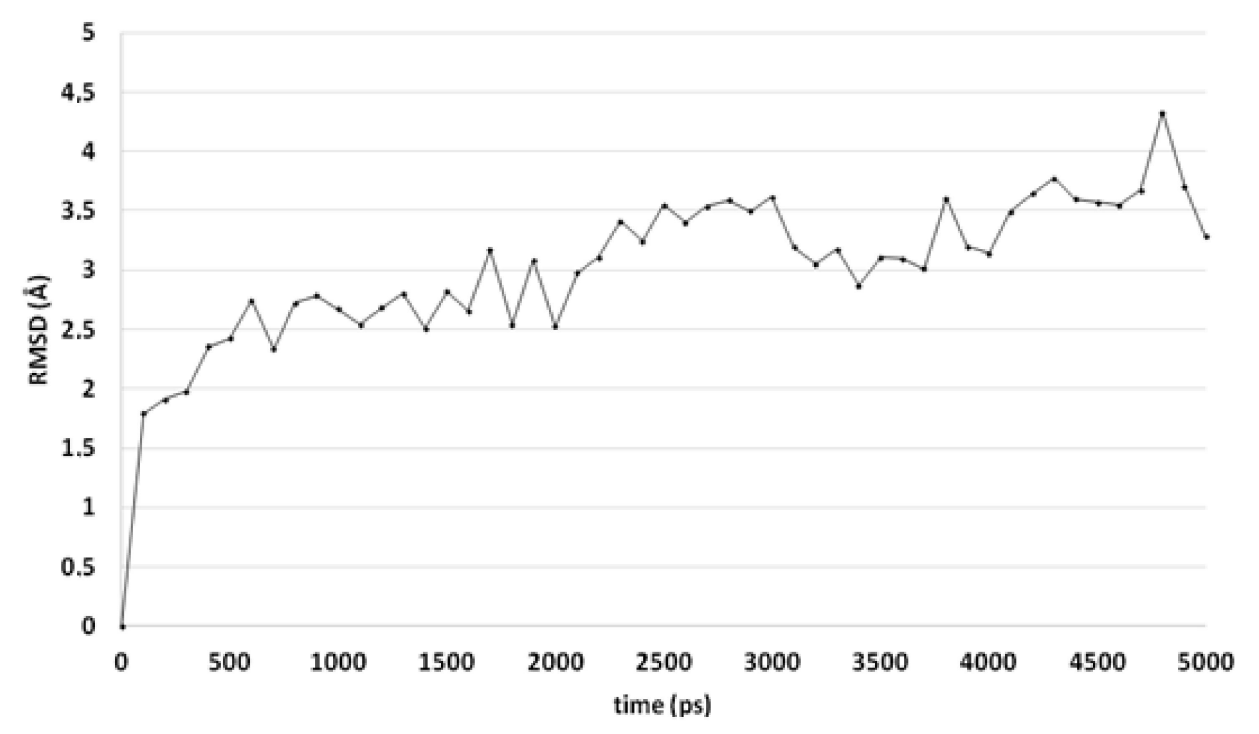

Figure 7. The RMSD of the ligand heavy atoms during the 5-ns molecular dynamics simulation of compound 40 in the active site of CaCYP51.

The residues in the active site that are in direct contact with ligands $4 \mathrm{~h}$ and 4o (CaCYP51a1) are conserved in both enzymes, but they have a slightly different conformation. Therefore, these poses have not been observed in CgCYP51a1, but they may be still possible after induced fit effects.

\subsubsection{Molecular Modeling Studies of the Candida glabrata $\beta$-CA Enzyme}

Docking studies indicate that the ligands may interact with the zinc-bound water molecule, as shown for compound 5k (Figure 8). This interaction is only possible if the ligand's hydroxyl group is in the $R$ isomeric conformation. The unsubstituted phenyl group forms a cation- $\pi$ interaction with Arg57. The ligand's peptide bond is near-linear and water-exposed and does not interact with the 
protein. The carbonyl group of the ligand forms an additional hydrogen bond with the side chain of Asn97. hydrophobic interactions are formed with Phe93.
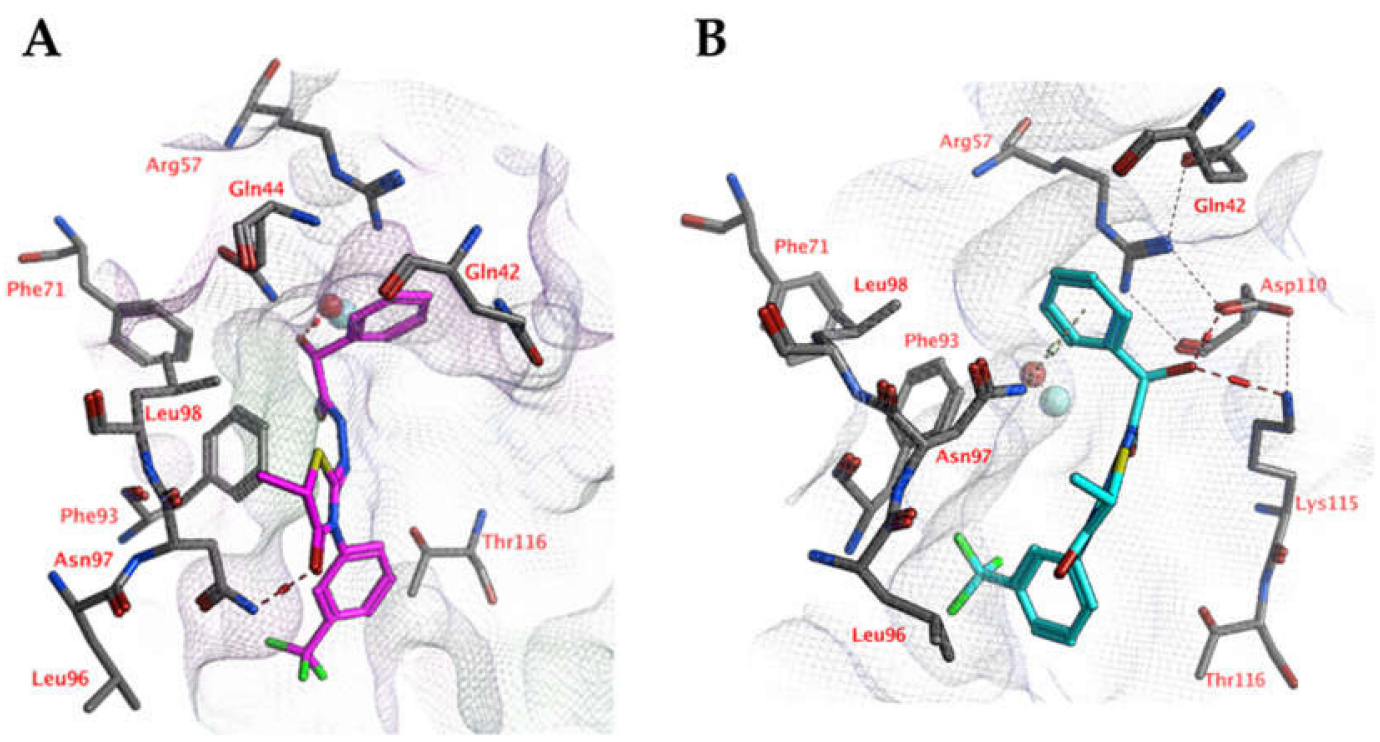

Figure 8. (A) The docked pose of compound 5k (purple) in the active site of CgNce103 (homology model). (B) The docked pose of compound 5k (turquoise) after a 5-ns molecular dynamics simulation. The pocket surface is indicated with a white mesh. hydrogen bonds are indicated in red dashed lines. The zinc ion is indicated in a turquoise sphere. The water molecule is indicated in a red sphere.

However, molecular dynamics simulations indicate that the docked pose may not be stable (Figure 9). The overall distance between the ligand's hydroxyl group and the active site zinc ion increases significantly during the first $500 \mathrm{ps}$ of the simulation, while the distances between the ligand's unsubstituted phenyl group (centroid) to the Arg57 side chain (atom Cz) and Asn97 side chain (atom ND2) decreases. As a result, cation- $\pi$ interactions with Arg57 and hydrogen-arene interactions with Asn97 can be formed after 500 ps.

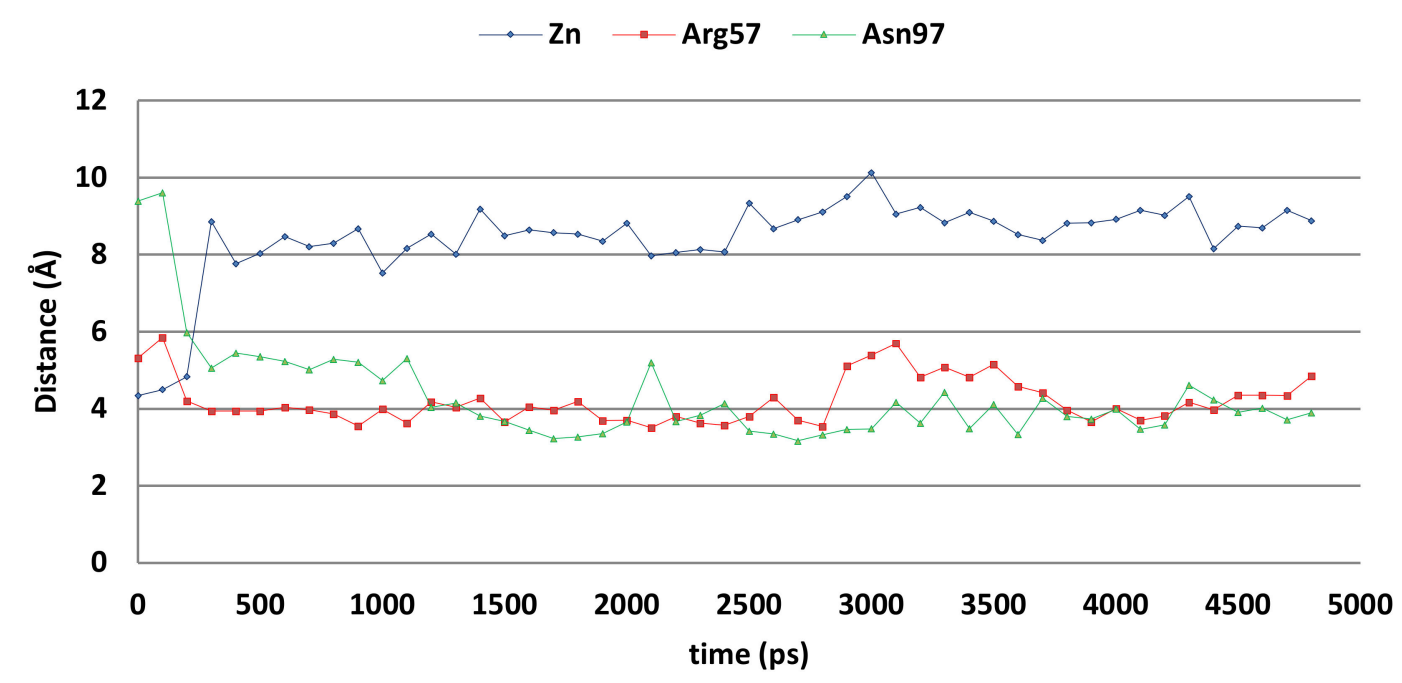

Figure 9. The distances between compound 5k and the zinc ion (blue), Arg57 sidechain (red), and Asn97 side chain (grey) of the CgNce103 active site during the 5-ns MD simulation.

Molecular modeling studies shed light on the putative targets of these compounds, highlighting how the introduction of specific chemical moieties in the thiazolidinone scaffold can efficiently contribute to a 
stronger interaction with well-established and crucial targets for the growth of the fungal cell. Moreover, the impact of the stereochemistry on the enzyme-inhibitor adducts pointed out that both the enzymes can stereoselectively recognize the substrates ( $\mathrm{S}$ isomer for CaCYP51a1 and $\mathrm{R}$ isomers for CgCYP51a1 and CgNce103).

\subsection{Enzyme Inhibition Studies of CgNce103 Compared to hCA I and II}

To better understand the putative mechanism of action of this scaffold and to confirm the in silico data, the thiazolidinones were also screened by means of a stopped-flow $\mathrm{CO}_{2}$ hydrase assay with the aim of assessing their potential to inhibit C. glabrata carbonic anhydrase (CgNce103) (Table 2). This target has been recently recognized as important for the fungal growth in $\mathrm{CO}_{2}$-enriched environments. Among the chemotypes designed for its inhibition in the literature, it was proposed and widely validated the use of zinc binding groups (e.g. sulfonamides and their bioisosteres, carboxylates and their derivatives, phenols, and so on). Thiazolidinones were recently assayed as potent antifungal agents [39,40], and some of them were tested as carbonic anhydrase inhibitors in order to discover and develop innovative mechanisms of inhibition [37,41]. From the data reported in Table 2, it is possible to extrapolate a very remarkable selectivity profile of our thiazolidinones against this fungal $\beta$-CA over the two ubiquitous human isoforms (hCA I and II) being the selectivity index (SI) for compound $4 \mathrm{~h}>1000$ (expressed as the ratio between $K_{\mathrm{I}}$ CA I or II and $K_{\mathrm{I}}$ CgNce103 values) and $>100$ for most of the other compounds. This aspect is very useful for medicinal chemists to design the structural requirements, providing selectivity among the large family of CA isozymes. Collectively, all the compounds (series 3 and 4$)$ were inactive against hCA $\mathrm{I}\left(K_{\mathrm{I}}>100 \mu \mathrm{M}\right)$ and poorly active against hCA II $\left(K_{\mathrm{I}}>47.4 \mu \mathrm{M}\right)$. On the contrary, the inhibition profile versus $\mathrm{CgNce103}$, except for two derivatives $\left(3 \mathrm{~g}, K_{\mathrm{I}} \mathrm{CgNce} 103=10.2 \mu \mathrm{M}\right.$ and $\left.3 \mathrm{l}, K_{\mathrm{I}} \mathrm{CgNce} 103=6.30 \mu \mathrm{M}\right)$, was characterized by nanomolar $K_{\mathrm{I}}$ values. In more detail, compounds with $\mathrm{R}_{1}=\mathrm{H}$ were slightly less efficient with respect to their counterparts with $\mathrm{R}_{1}=\mathrm{CH}_{3}$. Compound $3 \mathrm{o}\left(\mathrm{K}_{\mathrm{I}}=0.12 \mu \mathrm{M}\right)$ was the best representative of this series. Among $4 \mathrm{a}-4 \mathrm{k}$, there were several examples of potent nanomolar inhibitors, usually characterized by an electron-withdrawing meta- or para-substituent on the aryl ring at N3 of the core nucleus $(4 \mathrm{a}, 4 \mathrm{~g}$, $4 \mathrm{~h}$, and $4 \mathrm{k}$ ). Moreover, these compounds, despite being ten times less potent than acetazolamide (AAZ, $\left.K_{\mathrm{I}}=0.011 \mu \mathrm{M}\right)$ against $\mathrm{CgNce} 103$, displayed a better selectivity index toward human $\alpha$-CAs with respect to the same reference drug.

Table 2. Inhibition data of selected human and fungal CA isoforms (hCA I, hCA II, and CgNce103) by the most promising thiazolidinone compounds and the standard sulfonamide inhibitor acetazolamide (AAZ) by a stopped-flow $\mathrm{CO}_{2}$ hydrase assay.

\begin{tabular}{cccc}
\hline & \multicolumn{3}{c}{$K_{\mathbf{I}}^{*}(\mu \mathrm{M})$} \\
\cline { 2 - 4 } & hCA I & hCA II & CgNce103 \\
\hline $3 \mathrm{a}$ & $>100$ & $>100$ & 0.27 \\
\hline $3 \mathrm{~b}$ & $>100$ & $>100$ & 0.48 \\
\hline $3 \mathrm{c}$ & $>100$ & 76.7 & 0.38 \\
\hline $3 \mathrm{~d}$ & $>100$ & $>100$ & 0.32 \\
\hline $3 \mathrm{e}$ & $>100$ & 50.3 & 0.43 \\
\hline $3 \mathrm{f}$ & $>100$ & 62.9 & 0.51 \\
\hline $3 \mathrm{~g}$ & $>100$ & $>100$ & 10.2 \\
\hline $3 \mathrm{~h}$ & $>100$ & 55.7 & 0.82 \\
\hline $3 \mathrm{i}$ & $>100$ & 47.4 & 0.87 \\
\hline $3 \mathrm{k}$ & $>100$ & 79.3 & 0.41 \\
\hline
\end{tabular}


Table 2. Cont.

\begin{tabular}{cccc}
\hline & \multicolumn{3}{c}{$K_{\mathbf{I}}{ }^{*}(\mu \mathrm{M})$} \\
\cline { 2 - 4 } & hCA I & hCA II & CgNce103 \\
\hline 31 & $>100$ & $>100$ & 6.30 \\
\hline $3 \mathrm{~m}$ & $>100$ & $>100$ & 0.39 \\
\hline $3 \mathrm{o}$ & $>100$ & 82.8 & 0.12 \\
\hline $4 \mathrm{a}$ & $>100$ & $>100$ & 0.11 \\
\hline $4 \mathrm{c}$ & $>100$ & $>100$ & 0.48 \\
\hline $4 \mathrm{e}$ & $>100$ & $>100$ & 0.12 \\
\hline $4 \mathrm{f}$ & $>100$ & 68.2 & 0.56 \\
\hline $4 \mathrm{~g}$ & $>100$ & $>100$ & 0.11 \\
\hline $4 \mathrm{~h}$ & $>100$ & $>100$ & 0.50 \\
\hline $4 \mathrm{i}$ & $>100$ & $>100$ & 0.09 \\
\hline $4 \mathrm{k}$ & $>100$ & $>100$ & 0.69 \\
\hline AAZ & 0.25 & 0.012 & 0.011 \\
\hline
\end{tabular}

* Mean from 3 different assays, by a stopped-flow technique (errors were in the range of $\pm 5-10 \%$ of the reported values).

This information confirmed that sulfonamide-containing compounds are usually good CA inhibitors but endowed with limited isoform selectivity. Thus, our new scaffold can be further exploited for the design of new antifungal agents with the potential to inhibit selectively the fungal isoforms over human ones. Indeed, keeping in mind the structure-activity relationships extrapolated for this scaffold, researchers can exploit the structural requirements to display such biological activity. Moreover, our best-in-class compounds have an important significance for further clinical development, because their CA-based mechanism of action and isoform selectivity over human CAs could propose them as lead compounds for in vivo studies of fungal infections. These compounds can be used as coadjuvant or alternative therapy to classical azoles, limiting their dose, emerging resistance, and side effects.

\section{Materials and Methods}

\subsection{Bacterial and Fungal Strains and Culture Conditions}

The antimicrobial activity of these thiazolidinones was evaluated versus 24 clinical Gram-positive (S. aureus and S. epidermidis) and Gram-negative (E. coli and Enterobacter spp.) microorganisms. The antifungal activity of these derivatives was then tested versus 16 clinical fungal isolates belonging to the most relevant Candida spp. (C. albicans, C. tropicalis, C. parapsilosis, C. sakè, and C. glabrata). Prior to testing, each isolate was cultured on a selective medium to ensure purity and optimal growth, as previously reported [38]. The isolates were routinely identified by the morphological aspects of colonies and by biochemical identification. The used clinical isolates were collected from specimens of patients at the 'Azienda Policlinico Umberto I' (Sapienza University of Rome) and were obtained from hematology/oncology and surgery departments, which also included an intensive care unit. In particular, the samples were isolated from the upper and lower respiratory tract, blood, and indwelling venous catheters; the isolates were identified by conventional methodologies. Participating subjects gave their written informed consent for this study. 


\subsection{Antibacterial Activity}

The minimum inhibitory concentration (MIC) was determined by using the broth microdilution method in 96-well polystyrene microtitre plates (Eppendorf, hamburg, Germany) according to the Clinical \& Laboratory Standards Institute (CLSI) [42] guidelines. Briefly, bacterial overnight broth cultures were resuspended in Mueller-Hinton broth (Microbiology Systems, Cockeysville, MD, USA) to an optical density at $550 \mathrm{~nm}\left(\mathrm{OD}_{550}\right)$ of 0.8 corresponding to $1-5 \times 10^{8}$ colony-forming units $(\mathrm{CFU}) / \mathrm{mL}$. The broth cultures were subsequently diluted in Mueller-Hinton Broth to yield the appropriate density corresponding to $1-5 \times 10^{5} \mathrm{CFU} / \mathrm{mL}$ per well in a $100-\mu \mathrm{L}$ final volume. All derivatives were dissolved in DMSO and filtered through $0.22-\mu \mathrm{m}$ cellulose membrane filters (Corning, New York, NY, USA). Serial dilutions of each compound ranging from 128 to $0.5 \mu \mathrm{g} / \mathrm{mL}$ were added to each well. The plates included controls consisting of (i) bacteria without the addition of the compound, (ii) just the medium, and (iii) just the compound. Ceftazidime was used as a reference drug for comparison. The plates were incubated for 18 to $22 \mathrm{~h}$ at $37^{\circ} \mathrm{C}$. The minimum inhibitory concentration (MIC) for all isolates was defined as the lowest concentration of antibacterial agent that completely inhibited the growth of the organism, as detected by the unaided eye. Three independent experiments were performed in triplicate.

\subsection{Antifungal Activity}

The in vitro antifungal activities were determined by the broth microdilution method with sabouraud dextrose broth (BBL Microbiology Systems, Cockeysville, MD, USA), as recommended by the by the CLSI [43]. Ninety-six-well polystyrene microtitre plates containing serial dilutions of each compound were inoculated with each microorganism to yield the appropriate density $(1-5 \times$ $10^{3}$ cells $/ \mathrm{mL}$ ) in a $100-\mu \mathrm{L}$ final volume. Each plate included (i) fungi without the addition of the compound, (ii) just the medium, and (iii) just the compound. Topical and systemic antifungal reference drugs, clotrimazole and fluconazole, were inserted in the experiment. The plates were incubated for $24 \mathrm{~h}$ at $35^{\circ} \mathrm{C}$. The MIC for all isolates was defined as the lowest concentration of the antifungal agent that completely inhibited the growth of the organism, as detected by the unaided eye. Three independent experiments were performed in triplicate.

\subsection{Molecular Modeling Studies}

\subsubsection{Preparation of Ligand Structures}

Three-dimensional structures of all ligands, including all their stereoisomers, were prepared, and the most prevalent protonation state of the ligands at $\mathrm{pH} 7$ were calculated using the MOE Software package (v2019.0102, Chemical Computing Group, Inc, Montreal, QC, Canada). The ligands were energy minimized using a steepest-descent protocol (MMFF94x force field).

\subsubsection{Preparation of CaCYP51a1 and CgCYP51a1 Crystal Structures}

Crystal structures of Candida albicans (CaCYP51a1; PDB: 5v5z; $2.9 \AA$ A) and Candida glabrata (CgCYP51a1; PDB: 5jlc; $2.4 \AA$ A CYP51a1 enzymes, both in complex with itraconazole, have been obtained from the RCSB Protein Data Bank. Buffer molecules, ions, and water molecules were deleted if present (only in 5jlc), and the protein atoms, haem atoms, and iron atoms were retained. hydrogen atoms were added according to the protonate 3D protocol found in the MOE package [44]. Subsequently, the structures were subjected to energy minimization using a steepest-descent protocol (applied (AMBER14:EHT force field).

\subsubsection{Preparation of CgNce103 homology Models}

Homology models of CgNce103 (GenBank: CAG59355.1; 219 amino acids) were constructed using the crystal structure of the green alga Coccomyxa CA in complex with acetazolamide (CmCA; 3ucj; $1.85 \AA$ ) 
as previously described (50 models) using the MOE Software package [34]. The homology model with the highest contact score was selected, and steepest-descent energy minimization protocols were applied (AMBER14:EHT force field). All heavy atoms of acetazolamide (acquired from the 3ucj structure), the active site residues (all residues within $4.5 \AA$ of acetazolamide), the zinc ion, the zinc-binding his residues, and the protein backbone were fixed, and the other parts were minimized using a controlled release of position restraints. The minimized structure was used in the docking studies.

\subsection{Docking Studies}

Docking calculations were performed using the FlexX docking tool (v2.3.2; BioSolveIT GmbH, St. Augustin, Germany) within MOE. The binding pocket was defined as all residues within $6.5 \AA$ of the reference ligand acetazolamide (CgNce103 homology model) or itraconazole (CaCYP51a1 and CgCYP51a1 crystal structures). All ligands were docked fifty times, and the best-scoring three poses were subjected to refinement calculations. To this end, the docked ligand and binding pocket residues (defined as all residues within $6.5 \AA$ of the ligand) were energy-minimized and rescored using the GBVI/WSA force field [45].

\subsection{Molecular Dynamics Simulations}

All molecular dynamics simulations were performed using the Yasara Structure software package (v18.8.9, YASARA Biosciences GmbH, Vienna, Austria) [46,47]. The selected docked poses (ligand-enzyme complexes) were first placed into the center of a cuboid box with periodic boundary conditions (minimal distance of $10 \AA$ between the protein and boundary). Afterwards, both water molecules (density: $0.997 \mathrm{gr} / \mathrm{mL}$ ) and counter ions $(\mathrm{NaCl}$ ) were added to generate a solvated and neutral system. The system was energy-minimized using a steepest-descent protocol (AMBER14). The system was first heated from $0 \mathrm{~K}$ to $300 \mathrm{~K}$ during a 100-ps followed by a 200-ps equilibration simulation (position restraints on all protein and ligand heavy atoms). Finally, the system was simulated for $5 \mathrm{~ns}$ at a constant temperature ( $300 \mathrm{~K}$, Berendsen, default values) and pressure ( $1 \mathrm{bar}$, Berendsen, default values), without any position restrains (production run). The only restraints applied were distance restraints to keep the zinc ion in the correct orientation towards Cys53, his108, and Cys111 (default settings). The timestep was set to $2 \times 1.25 \mathrm{fs}$, and all bonds were constrained using the LINCS algorithm. Snapshots were taken every 100 ps of the 5 -ns production run.

\subsection{Enzyme Inhibition Assays}

An applied photophysics stopped-flow instrument has been used for assaying the fungal and human CA-catalyzed $\mathrm{CO}_{2}$ hydration activity [48]. Phenol red $(0.2 \mathrm{mM})$ has been used as the indicator, working at the absorbance maximum of $557 \mathrm{~nm}$, with 20-mM hEPES (pH 7.5 for $\alpha$-CAs) or TRIS ( $\mathrm{pH} 8.3$ for the $\beta-\mathrm{CA}$ ) as buffers and $20-\mathrm{mM} \mathrm{NaClO}_{4}$ (for maintaining constant the ionic strength), following the initial rates of the CA-catalyzed $\mathrm{CO}_{2}$ hydration reaction for a period of $10-100 \mathrm{~s}$. The $\mathrm{CO}_{2}$ concentrations ranged from 1.7 to $17 \mathrm{mM}$ for the determination of the kinetic parameters and inhibition constants. In particular, $\mathrm{CO}_{2}$ was bubbled in distilled deionized water for 30 min until saturation. $\mathrm{A} \mathrm{CO}_{2}$ kit (Sigma-Aldrich, Milan, Italy) was used to measure the concentration in serially diluted solutions from the saturated one at the same temperature. For each inhibitor, at least six traces of the initial $5-10 \%$ of the reaction have been used for determining the initial velocity. The uncatalyzed rates were determined in the same manner and subtracted from the total observed rates. Stock solutions of the inhibitor $(1 \mu \mathrm{M})$ were prepared in distilled-deionized water, and dilutions up to $0.1 \mathrm{nM}$ were done thereafter with the assay buffer. Inhibitor and enzyme solutions were preincubated together for $15 \mathrm{~min}$ at room temperature prior to the assay in order to allow for the formation of the E-I complex or for the eventual active site-mediated hydrolysis of the inhibitor. The inhibition constants were obtained by the nonlinear least-squares methods using PRISM 3 and the Cheng-Prusoff equation and represent the average from at least three different determinations. All recombinant CA isoforms were obtained in-house, as previously reported $[49,50]$. 


\section{Conclusions}

We synthesized and tested 26 new thiazolidinones against Candida spp. and several Gram-positive and Gram-negative bacteria. The compounds showed selective antifungal activity, while lacking strong antibacterial activity. Molecular docking and molecular dynamics studies were performed on Candida CaCYP51a1, CgCYP51a1, and CgNce103 enzymes in order to evaluate the putative mechanism of action. For CYP51a1 enzymes, the thiazolidinones could bind both to the entrance of the active site, as well as in the active site. In the latter case, the compounds were able to form an interaction with the haem iron atom. For CgNce013, no docked poses were found in which the ligands directly interacted with the active-site zinc ion. Docked poses in which the ligand forms interactions with a zinc-bound water molecule were not stable during 5-ns molecular dynamics simulations. Nevertheless, the ligands may be able to bind close to the zinc-bound water molecule without a direct interaction, while they form hydrogen-arene interactions with Asn 97 and cation- $\pi$ interactions with Arg57. CgNce103 enzyme inhibition assays revealed that these thiazolidinones indeed inhibit this fungal CA enzyme with $K_{\mathrm{I}}$ values in the 0.1-10 $\mu \mathrm{M}$ range. Collectively, this new class of compounds can be further developed as innovative antifungal agents endowed with an alternative mechanism of action with respect to azoles.

Author Contributions: Conceptualization, Ö.G.-A., C.T.S. and A.A. (Atilla Akdemir); Synthesis Ö.G.-A and K.D.-Y., Molecular modeling, A.A. (Atilla Akdemir); Enzyme Inhibition Assays: A.A. (Andrea Angeli) and C.T.S.; Antifungal and Antibacterial Assays: S.C. and R.G.; Writing-Original Draft Preparation, A.A. (Atilla Akdemir) and Ö.G.A.; Writing-Review \& Editing, A.A. (Atilla Akdemir) and Ö.G.-A.; Supervision, Ö.G.-A.; Project Administration, Ö.G.-A.; Funding Acquisition, Ö.G.-A. All authors have read and agreed to the published version of the manuscript.

Funding: This work was supported by Research Fund of Istanbul University (Project Number BEK-2017- 24737).

Conflicts of Interest: The authors declare no conflicts of interest.

\section{References}

1. Lamoth, F.; Lockhart, S.R.; Berkow, E.L.; Calandra, T. Changes in the epidemiological landscape of invasive candidiasis. J. Antimicrob. Chemother. 2018, 73, i4-i13. [CrossRef]

2. Barac, A.; Cevik, M.; Colovic, N.; Lekovic, D.; Stevanovic, G.; Micic, J.; Rubino, S. Investigation of a healthcare-associated Candida tropicalis candidiasis cluster in a haematology unit and a systematic review of nosocomial outbreaks. Mycoses 2020, 63, 326-333. [CrossRef] [PubMed]

3. Pfaller, M.A.; Diekema, D.J.; Turnidge, J.D.; Castanheira, M.; Jones, R.N. Twenty years of the SENTRY antifungal surveillance program: Results for Candida species from 1997-2016. Open Forum Infect. Dis. 2019, 6, S79-S94. [CrossRef] [PubMed]

4. Hendrickson, J.A.; hu, C.; Aitken, S.L.; Beyda, N. Antifungal resistance: A concerning trend for the present and future. Curr. Infect. Dis. Rep. 2019, 21, 47. [CrossRef] [PubMed]

5. Schwartz, I.S.; Patterson, T.F. The Emerging threat of antifungal resistance in transplant infectious diseases. Curr. Infect. Dis. Rep. 2018, 20, 2. [CrossRef] [PubMed]

6. Fisher, M.C.; hawkins, N.J.; Sanglard, D.; Gurr, S.J. Worldwide emergence of resistance to antifungal drugs challenges human health and food security. Science 2018, 360, 739-742. [CrossRef]

7. Brown, G.D.; Denning, D.W.; Gow, N.A.R.; Levitz, S.M.; Netea, M.G.; White, T.C. hidden killers: human fungal infections. Sci. Transl. Med. 2012, 4, 165rv13. [CrossRef]

8. Spampinato, C.; Leonardi, D. Candida infections, causes, targets, and resistance mechanisms: Traditional and alternative antifungal agents. Biomed Res. Int. 2013, 2013, 13. [CrossRef]

9. Pristov, K.E.; Ghannoum, M.A. Resistance of Candida to azoles and echinocandins worldwide. Clin. Microbiol. Infect. 2019, 25, 792-798. [CrossRef]

10. Capasso, C.; Supuran, C.T. Bacterial, fungal and protozoan carbonic anhydrases as drug targets. Expert Opin. Ther. Targets 2015, 19, 1689-1704. [CrossRef]

11. Capasso, C.; Supuran, C.T. Anti-infective carbonic anhydrase inhibitors: A patent and literature review. Expert Opin. Ther. Pat. 2013, 23, 693-704. [CrossRef] [PubMed] 
12. Akocak, S.; Supuran, C.T. Activation of $\alpha-, \beta-, \gamma-\delta-, \zeta-$ and $\eta$ - class of carbonic anhydrases with amines and amino acids: A review. J. Enzyme Inhib. Med. Chem. 2019, 34, 1652-1659. [CrossRef]

13. Cottier, F.; Leewattanapasuk, W.; Kemp, L.R.; Murphy, M.; Supuran, C.T.; Kurzai, O.; Mühlschlegel, F.A. Carbonic anhydrase regulation and $\mathrm{CO}_{2}$ sensing in the fungal pathogen Candida glabrata involves a novel Rca1p ortholog. Bioorganic Med. Chem. 2013, 21, 1549-1554. [CrossRef] [PubMed]

14. Dostál, J.; Brynda, J.; Blaha, J.; Macháček, S.; heidingsfeld, O.; Pichová, I. Crystal structure of carbonic anhydrase CaNce103p from the pathogenic yeast Candida albicans. BMC Struct. Biol. 2018, 18, 14. [CrossRef] [PubMed]

15. Rami, M.; Innocenti, A.; Montero, J.L.; Scozzafava, A.; Winum, J.Y.; Supuran, C.T. Synthesis of rhodamine B-benzenesulfonamide conjugates and their inhibitory activity against human $\alpha$ - and bacterial/fungal $\beta$-carbonic anhydrases. Bioorganic Med. Chem. Lett. 2011, 21, 5210-5213. [CrossRef]

16. Pacchiano, F.; Carta, F.; Vullo, D.; Scozzafava, A.; Supuran, C.T. Inhibition of $\beta$-carbonic anhydrases with ureido-substituted benzenesulfonamides. Bioorganic Med. Chem. Lett. 2011, 21, 102-105. [CrossRef]

17. Vullo, D.; Leewattanapasuk, W.; Mühlschlegel, F.A.; Mastrolorenzo, A.; Capasso, C.; Supuran, C.T. Carbonic anhydrase inhibitors: Inhibition of the $\beta$-class enzyme from the pathogenic yeast Candida glabrata with sulfonamides, sulfamates and sulfamides. Bioorganic Med. Chem. Lett. 2013, 23, 2647-2652. [CrossRef]

18. Angeli, A.; Pinteala, M.; Maier, S.S.; Del Prete, S.; Capasso, C.; Simionescu, B.C.; Supuran, C.T. Inhibition of $\alpha-, \beta-, \gamma_{-}, \delta-, \zeta-$ and $\eta$-class carbonic anhydrases from bacteria, fungi, algae, diatoms and protozoans with famotidine. J. Enzyme Inhib. Med. Chem. 2019, 34, 644-650. [CrossRef]

19. Bua, S.; Osman, S.M.; AlOthman, Z.; Supuran, C.T.; Nocentini, A. Benzenesulfonamides incorporating nitrogenous bases show effective inhibition of $\beta$-carbonic anhydrases from the pathogenic fungi Cryptococcus neoformans, Candida glabrata and Malassezia globosa. Bioorg. Chem. 2019, 86, 39-43. [CrossRef]

20. Güzel, Ö.; Maresca, A.; hall, R.A.; Scozzafava, A.; Mastrolorenzo, A.; Mühlschlegel, F.A.; Supuran, C.T. Carbonic anhydrase inhibitors. The $\beta$-carbonic anhydrases from the fungal pathogens Cryptococcus neoformans and Candida albicans are strongly inhibited by substituted-phenyl-1H-indole-5-sulfonamides. Bioorganic Med. Chem. Lett. 2010, 20, 2508-2511. [CrossRef]

21. Innocenti, A.; hall, R.A.; Schlicker, C.; Scozzafava, A.; Steegborn, C.; Mühlschlegel, F.A.; Supuran, C.T. Carbonic anhydrase inhibitors. Inhibition and homology modeling studies of the fungal $\beta$-carbonic anhydrase from Candida albicans with sulfonamides. Bioorganic Med. Chem. 2009, 17, 4503-4509. [CrossRef] [PubMed]

22. Innocenti, A.; Leewattanapasuk, W.; Mühlschlegel, F.A.; Mastrolorenzo, A.; Supuran, C.T. Carbonic anhydrase inhibitors. Inhibition of the $\beta$-class enzyme from the pathogenic yeast Candida glabrata with anions. Bioorganic Med. Chem. Lett. 2009, 19, 4802-4805. [CrossRef] [PubMed]

23. Sechi, M.; Innocenti, A.; Pala, N.; Rogolino, D.; Carcelli, M.; Scozzafava, A.; Supuran, C.T. Inhibition of $\alpha$-class cytosolic human carbonic anhydrases I, II, IX and XII, and $\beta$-class fungal enzymes by carboxylic acids and their derivatives: New isoform-I selective nanomolar inhibitors. Bioorganic Med. Chem. Lett. 2012, 22, 5801-5806. [CrossRef] [PubMed]

24. Carta, F.; Innocenti, A.; hall, R.A.; Mühlschlegel, F.A.; Scozzafava, A.; Supuran, C.T. Carbonic anhydrase inhibitors. Inhibition of the $\beta$-class enzymes from the fungal pathogens Candida albicans and Cryptococcus neoformans with branched aliphatic/aromatic carboxylates and their derivatives. Bioorganic Med. Chem. Lett. 2011, 21, 2521-2526. [CrossRef] [PubMed]

25. Innocenti, A.; hall, R.A.; Schlicker, C.; Mühlschlegel, F.A.; Supuran, C.T. Carbonic anhydrase inhibitors. Inhibition of the $\beta$-class enzymes from the fungal pathogens Candida albicans and Cryptococcus neoformans with aliphatic and aromatic carboxylates. Bioorganic Med. Chem. 2009, 17, 2654-2657. [CrossRef] [PubMed]

26. Monti, S.M.; Maresca, A.; Viparelli, F.; Carta, F.; De Simone, G.; Mühlschlegel, F.A.; Scozzafava, A.; Supuran, C.T. Dithiocarbamates are strong inhibitors of the beta-class fungal carbonic anhydrases from Cryptococcus neoformans, Candida albicans and Candida glabrata. Bioorganic Med. Chem. Lett. 2012, 22, 859-862. [CrossRef]

27. Supuran, C.T. Bortezomib inhibits bacterial and fungal $\beta$-carbonic anhydrases. Bioorganic Med. Chem. 2016, 24, 4406-4409. [CrossRef]

28. Nocentini, A.; Cadoni, R.; Del Prete, S.; Capasso, C.; Dumy, P.; Gratteri, P.; Supuran, C.T.; Winum, J.Y. Benzoxaboroles as efficient inhibitors of the $\beta$-carbonic anhydrases from pathogenic fungi: Activity and modeling study. ACS Med. Chem. Lett. 2017, 8, 1194-1198. [CrossRef] 
29. Innocenti, A.; Winum, J.Y.; hall, R.A.; Mühlschlegel, F.A.; Scozzafava, A.; Supuran, C.T. Carbonic anhydrase inhibitors. Inhibition of the fungal $\beta$-carbonic anhydrases from Candida albicans and Cryptococcus neoformans with boronic acids. Bioorganic Med. Chem. Lett. 2009, 19, 2642-2645. [CrossRef]

30. Davis, R.A.; hofmann, A.; Osman, A.; hall, R.A.; Mühlschlegel, F.A.; Vullo, D.; Innocenti, A.; Supuran, C.T.; Poulsen, S.A. Natural product-based phenols as novel probes for mycobacterial and fungal carbonic anhydrases. J. Med. Chem. 2011, 54, 1682-1692. [CrossRef]

31. Alissa, S.A.; Alghulikah, H.A.; Alothman, Z.A.; Osman, S.M.; Del Prete, S.; Capasso, C.; Nocentini, A.; Supuran, C.T. Phosphonamidates are the first phosphorus-based zinc binding motif to show inhibition of $\beta$-class carbonic anhydrases from bacteria, fungi, and protozoa. J. Enzyme Inhib. Med. Chem. 2020, 35, 59-64. [CrossRef] [PubMed]

32. Ceruso, M.; Carta, F.; Osman, S.M.; Alothman, Z.; Monti, S.M.; Supuran, C.T. Inhibition studies of bacterial, fungal and protozoan $\beta$-class carbonic anhydrases with Schiff bases incorporating sulfonamide moieties. Bioorganic Med. Chem. 2015, 23, 4181-4187. [CrossRef]

33. Carta, F.; Osman, S.M.; Vullo, D.; AlOthman, Z.; Del Prete, S.; Capasso, C.; Supuran, C.T. Poly(amidoamine) dendrimers show carbonic anhydrase inhibitory activity against $\alpha-, \beta-, \gamma$ - and $\eta$-class enzymes. Bioorganic Med. Chem. 2015, 23, 6794-6798. [CrossRef] [PubMed]

34. Akdemir, A.; Güzel-Akdemir, Ö.; Karalı, N.; Supuran, C.T. Isatin analogs as novel inhibitors of Candida spp. $\beta$-carbonic anhydrase enzymes. Bioorganic Med. Chem. 2016, 24, 1648-1652. [CrossRef] [PubMed]

35. Akdemir, A.; Angeli, A.; Göktaş, F.; Eraslan Elma, P.; Karalı, N.; Supuran, C.T. Novel 2-indolinones containing a sulfonamide moiety as selective inhibitors of candida $\beta$-carbonic anhydrase enzyme. J. Enzyme Inhib. Med. Chem. 2019, 34, 528-531. [CrossRef]

36. Fesatidou, M.; Petrou, A.; Geronikaki, A. heterocycle compounds with antimicrobial activity. Curr. Pharm. Des. 2020, 26. [CrossRef]

37. Güzel-Akdemir, Ö.; Angeli, A.; Demir, K.; Supuran, C.T.; Akdemir, A. Novel thiazolidinone-containing compounds, without the well-known sulphonamide zinc-binding group acting as human carbonic anhydrase IX inhibitors. J. Enzyme Inhib. Med. Chem. 2018, 33, 1299-1308. [CrossRef]

38. Secci, D.; Carradori, S.; Bizzarri, B.; Chimenti, P.; De Monte, C.; Mollica, A.; Rivanera, D.; Zicari, A.; Mari, E.; Zengin, G.; et al. Novel 1,3-thiazolidin-4-one derivatives as promising anti-Candida agents endowed with anti-oxidant and chelating properties. Eur. J. Med. Chem. 2016, 117, 144-156. [CrossRef]

39. De Monte, C.; Carradori, S.; Bizzarri, B.; Bolasco, A.; Caprara, F.; Mollica, A.; Rivanera, D.; Mari, E.; Zicari, A.; Akdemir, A.; et al. Anti-Candida activity and cytotoxicity of a large library of new N-substituted-1,3-thiazolidin-4-one derivatives. Eur. J. Med. Chem. 2016, 107, 82-96. [CrossRef]

40. Abo-Ashour, M.F.; Eldehna, W.M.; George, R.F.; Abdel-Aziz, M.M.; Elaasser, M.M.; Abdel Gawad, N.M.; Gupta, A.; Bhakta, S.; Abou-Seri, S.M. Novel indole-thiazolidinone conjugates: Design, synthesis and whole-cell phenotypic evaluation as a novel class of antimicrobial agents. Eur. J. Med. Chem. 2018, 160, 49-60. [CrossRef]

41. Yılmaz, Ö.; Özbaş Turan, S.; Akbua, J.; Tiber, P.M.; Orun, O.; Supuran, C.T.; Küçükgüzel, G. Synthesis of pro-apoptotic indapamide derivatives as anticancer agents. J. Enzyme Inhib. Med. Chem. 2015, 30, 967-980. [CrossRef] [PubMed]

42. Clinical and Laboratory Standards Institute (CLSI). Performance Standards for Antimicrobial Susceptibility Testing; Twenty-Ninth Informational Supplement; M100-S29; Clinical and Laboratory Standards Institute: Wayne, PA, USA, 2019.

43. Arendrup, M.C.; Cuenca-Estrella, M.; Lass-Flörl, C.; hope, W.; Arendrup, M.C.; hope, W.W.; Flörl, C.; Cuenca-Estrella, M.; Arikan, S.; Barchiesi, F.; et al. EUCAST technical note on the EUCAST definitive document EDef 7.2: Method for the determination of broth dilution minimum inhibitory concentrations of antifungal agents for yeasts EDef 7.2 (EUCAST-AFST). Clin. Microbiol. Infect. 2012, 18, E246-E247. [CrossRef] [PubMed]

44. Labute, P. Protonate3D: Assignment of ionization states and hydrogen coordinates to macromolecular structures. Proteins Struct. Funct. Bioinforma. 2009, 75, 187-205. [CrossRef] [PubMed]

45. Labute, P. The generalized born/volume integral implicit solvent model: Estimation of the free energy of hydration using London dispersion instead of atomic surface area. J. Comput. Chem. 2008, 29, 1693-1698. [CrossRef] 
46. Krieger, E.; Vriend, G. New ways to boost molecular dynamics simulations. J. Comput. Chem. 2015, 36, 996-1007. [CrossRef]

47. Krieger, E.; Vriend, G. YASARA View-Molecular graphics for all devices-From smartphones to workstations. Bioinformatics 2014, 30, 2981-2982. [CrossRef]

48. Khalifah, R.G. The carbon dioxide hydration activity of carbonic anhydrase. I. Stop flow kinetic studies on the native human isoenzymes B and C. J. Biol. Chem. 1971, 246, 2561-2573.

49. Angeli, A.; Abbas, G.; Del Prete, S.; Carta, F.; Capasso, C.; Supuran, C.T. Acyl selenoureido benzensulfonamides show potent inhibitory activity against carbonic anhydrases from the pathogenic bacterium Vibrio cholerae. Bioorg. Chem. 2017, 75, 170-172. [CrossRef]

50. Angeli, A.; Abbas, G.; del Prete, S.; Capasso, C.; Supuran, C.T. Selenides bearing benzenesulfonamide show potent inhibition activity against carbonic anhydrases from pathogenic bacteria Vibrio cholerae and Burkholderia pseudomallei. Bioorg. Chem. 2018, 79, 319-322. [CrossRef]

(C) 2020 by the authors. Licensee MDPI, Basel, Switzerland. This article is an open access article distributed under the terms and conditions of the Creative Commons Attribution (CC BY) license (http://creativecommons.org/licenses/by/4.0/). 